\title{
Immunological Control of Viral Infections in Bats and the Emergence of Viruses Highly Pathogenic to Humans
}

\author{
Tony Schountz ${ }^{1 *}$, Michelle L. Baker ${ }^{2}$, John Butler ${ }^{3}$ and Vincent Munster ${ }^{4}$ \\ 'Arthropod-Borne and Infectious Diseases Laboratory, Department of Microbiology, Immunology and Pathology, Colorado \\ State University, Fort Collins, CO, United States, ${ }^{2}$ Australian Animal Health Laboratory, Health and Biosecurity Business Unit, \\ Commonwealth Scientific and Industrial Research Organisation, Geelong, VIC, Australia, ${ }^{3}$ Department of Microbiology, \\ Carver College of Medicine, University of lowa, lowa City, IA, United States, ${ }^{4}$ Virus Ecology Unit, Rocky Mountain \\ Laboratories, National Institutes of Health, Hamilton, MT, United States
}

OPEN ACCESS

Edited by:

Greg Woods,

University of Tasmania,

Australia

Reviewed by:

Maria Forlenza,

Wageningen University and

Research, Netherlands

Alison Kell,

University of Washington,

United States

William Lee,

Wadsworth Center

United States

${ }^{*}$ Correspondence:

Tony Schountz

tony.schountz@colostate.edu

Specialty section:

This article was submitted

to Comparative Immunology,

a section of the journal

Frontiers in Immunology

Received: 17 July 2017

Accepted: 22 August 2017

Published: 11 September 2017

Citation:

Schountz T, Baker ML, Butler J and Munster V (2017) Immunological

Control of Viral Infections in Bats and the Emergence of Viruses Highly

Pathogenic to Humans.

Front. Immunol. 8:1098. doi: 10.3389/fimmu.2017.01098
Bats are reservoir hosts of many important viruses that cause substantial disease in humans, including coronaviruses, filoviruses, lyssaviruses, and henipaviruses. Other than the lyssaviruses, they do not appear to cause disease in the reservoir bats, thus an explanation for the dichotomous outcomes of infections of humans and bat reservoirs remains to be determined. Bats appear to have a few unusual features that may account for these differences, including evidence of constitutive interferon (IFN) activation and greater combinatorial diversity in immunoglobulin genes that do not undergo substantial affinity maturation. We propose these features may, in part, account for why bats can host these viruses without disease and how they may contribute to the highly pathogenic nature of bat-borne viruses after spillover into humans. Because of the constitutive IFN activity, bat-borne viruses may be shed at low levels from bat cells. With large naive antibody repertoires, bats may control the limited virus replication without the need for rapid affinity maturation, and this may explain why bats typically have low antibody titers to viruses. However, because bat viruses have evolved in high IFN environments, they have enhanced countermeasures against the IFN response. Thus, upon infection of human cells, where the IFN response is not constitutive, the viruses overwhelm the IFN response, leading to abundant virus replication and pathology.

Keywords: bats, Chiroptera, zoonosis, antibody repertoire, emerging infectious disease, virus ecology

Bats have gained attention in recent years as reservoir or suspected reservoir hosts of many highimpact human pathogenic viruses that cause outbreaks and epidemics with high mortality $(1,2)$. In terms of viral species richness and zoonotic potential, bats may be the most important mammalian sources $(3,4)$. Each of these viruses, including the ebolaviruses, Marburg virus, severe acute respiratory syndrome and Middle East respiratory syndrome coronaviruses, rabies and other lyssaviruses, and Hendra and Nipah viruses, is thought to circulate in certain species of bats without significant disease. Chiroptera, to which bats belong, is the second largest mammalian order, with about 1,200 species. Bats originated about 80 million years ago (mya) and substantial radial divergence ensued soon after the K-T extinction event about 66 mya (5). Consequently, bats have been on independent evolutionary trajectories for most of the history of mammals. They belong to the mammalian superorder Laurasiatheria that includes ungulates and canines, 
whereas rodents and primates belong to the superorder Euarchontoglires; these superorders diverged about 90 mya. Genome and transcriptome analyses suggest the immune systems of bats are substantially similar to those of other mammals; however, there are some significant differences, including the loss of the PYHIN locus that has the AIM2 cytosolic DNA sensor and inflammasome genes, loss of killer cell immunoglobulinlike (KIR), and killer cell lectin-like (KLR) receptor loci used by NK cells, expanded immunoglobulin heavy-chain VDJ segments and contraction of the interferon- $\alpha$ (IFN $\alpha$ ) locus (6-11). Although bats share many immunological features with other mammals, little research into their immune systems or responses has been conducted and there are no well-developed bat research models to study infectious agents $(12,13)$.

Often, in zoonotic virus/reservoir host relationships, which have been best studied in rodents and primates (14-16), each virus is hosted by individuals of one or only a few species. There are exceptions, including slowly replicating viruses, such as rabies virus. However, viruses, like all other biological entities, are subject to the pressures of evolution and are likely genetically and biochemically adapted ("optimized") to circulate within their reservoir host populations to either cause persistent infection (often for the life of the host), or to replicate and be shed for a sufficient period to allow transmission to other susceptible hosts, without causing substantial disease within the population (17). They typically do not elicit robust immune responses in their reservoirs, which could lead to viral clearance or immunopathology. When spillover of pathogenic viruses to humans or other non-reservoir species occurs, they are not biochemically optimized for the new host cells, which can lead to disease and death, or immune clearance.

Because of the occurrence of severe human diseases caused by some of the bat-borne viruses, an important question is; how do bats host these viruses without becoming diseased? The answer to this question is likely complicated and will vary between species of bats and species of viruses. In rodent reservoirs of pathogenic hantaviruses, in which the viruses establish persistent infection without meaningful pathology (18-22), the immune response is slow to develop (21) and is mediated by Fox$\mathrm{p}^{+}$, TGF $\beta$-expressing regulatory T (Treg) cells, which counter inflammatory disease $(23,24)$ but at the expense of sterilizing immunity. Do bats have Treg cells? If so, do bat viruses also elicit Treg responses in their reservoir hosts? T cell genes are found in bats, but there are no publications demonstrating antigenspecific T cell activities in bats. The lack of such studies underlies a significant deficit in the study of bat immune responses, considering the functional subsets of $\mathrm{T}$ cells that have been identified in other species (e.g., Th1, Th2, Th17, NKT, Tfh, CTL, etc.) and the effector functions mediated by $\mathrm{T}$ cells, including $\mathrm{T}$ cell help, inflammation, chemotaxis, and augmentation of macrophage activities such as phagocytosis and killing of microbes.

Even less is known about NK cells in bats. Does the loss of KIR/KLR genes in bats (8) mean that NK cells use alternative receptors to recognize $\mathrm{MHC}$ class I for activation and inhibition? Do bat NK cells have the same effector functions found in other species, such as granzyme-mediated cytolysis and antibodydependent cell cytotoxicity? Genes for granzymes A and B and
CD16 (FcR $\gamma$ III) are found in bats $(6,7)$; thus, it is likely that bat NK cells are functionally similar to other species in this regard. Until methods are developed to assess T cell and NK cell functions in bats, our understanding of bat virus infections of reservoir hosts will be severely limited.

Pathogenic bat-borne viruses encode immune modulating accessory proteins that often target the innate antiviral responses of infected cells. It is thought that these proteins are contributory factors of human disease ("virulence factors") (25-32); however, because they evolved in their bat reservoirs (i.e., biochemically optimized), their impacts on the orthologous proteins of humans must somehow be different; otherwise, there would not be differential outcomes in bats (no disease) and humans (disease).

\section{THE “FLIGHT AS FEVER” HYPOTHESIS}

One proposed explanation for the lack of disease in virus-infected bats is the "flight as fever" hypothesis that suggests elevated body temperature during flight somehow mimics the effects of the fever response (33). However, the fever response after infection is much more sophisticated than simply elevated body temperature. In other mammals that have been studied, the production of interferons (IFN), interleukin-1, and prostaglandins have already occurred by the time fever is detectable $(34,35)$. There is no evidence that these effector molecules are expressed by bats during flight. Moreover, viral infections are complex processes; thus, it is unlikely that elevated body temperature alone is sufficient to explain how bats can host these viruses without signs of disease. The only experimental work assessing this effect showed that increasing incubation temperature of bat cells does not affect their ability to support ebolavirus replication (36). Although there is no experimental evidence supporting the flight as fever hypothesis, some have speculated this provides a metabolic mechanism for bats to host these viruses without disease (37).

\section{THE “ALWAYS ON” IFN SYSTEM OF BATS}

An interesting feature of pteropid bats is that parts of the type I IFN system appear to be constitutively active and it has been hypothesized that this "always on" activity may hamper early viral replication (10). We have also observed signatures of IFN receptor pathway activation in uninfected primary kidney cells cultured from Jamaican fruit bats (Artibeus jamaicensis), including constitutive STAT1 phosphorylation (unpublished data). In other mammals that have been examined, the type I IFN loci have undergone expansion by tandem duplication events, leading to multiple copies of Ifna genes. However, in bats there is compelling evidence that the type I IFN locus has undergone contraction leading to fewer Ifna genes (10). Despite this contraction, Ifna basal gene expression in bats is elevated relative to humans and rodents, as are the levels of many IFN-stimulated genes (ISG). The constitutive Ifna expression appears to induce a profile of ISGs that is not inflammatory, and this may be one of the reasons why Ifna expression can be elevated without leading to chronic inflammatory pathology. Furthermore, as the levels of IFN $\alpha$ protein expressed by bat cells remains to be determined, it is possible that much of the Ifna mRNA remains untranslated, 
providing a source of transcripts for rapid translation when required. In addition, the type III IFN response appears to be restricted to immune cells and epithelial cells, and can be activated independently of type I IFN signaling $(38,39)$. Collectively, these aspects of the innate immune system suggest that bat cells are poised to respond to viral infections immediately, which may restrict, but not prevent, viral replication. It is unknown why bat IFN pathways are constitutively active but some species of bats can have extraordinarily high population densities with extensive mutual grooming behavior. Because transmission of infectious agents is related to population density, it may be evolutionarily favorable for bats to hamper virus replication and shedding to limit transmission within a population. However, viruses must also be able to sufficiently evade the response to transmit within the bat population; otherwise, they would be driven to extinction. Thus, it is likely that bat virus accessory proteins are finely tuned to modulate bat antiviral responses.

\section{IMMUNOGLOBULIN REPERTOIRES OF BATS}

The germline immunoglobulin loci of mammals contain tandem variable $(\mathrm{V})$, diversity $(\mathrm{D})$, and joining $(\mathrm{J})$ gene segments that recombine during $\mathrm{B}$ cell development in the bone marrow to generate VDJ rearrangements at the immunoglobulin heavychain locus, and VJ rearrangements at the light chain locus (40). The number of segments varies between species (Table 1), and not all segments are functional. For example, humans have 87 immunoglobulin heavy-chain $\mathrm{V}$ segments, but only about 40 are functional. $\mathrm{V}(\mathrm{D}) \mathrm{J}$ recombination generates the naive $B$ cell immunoglobulin repertoire of an individual with, in humans, about 2 million unique immunoglobulin specificities that typically have an IgM heavy chain (41). The result, termed combinatorial diversity, occurs prior to, and is independent of, the antigen stimulation of an immune response. Swine, on the other hand, have far fewer heavy-chain gene segments, with seven functional $\mathrm{V}$ segments, two $\mathrm{D}$ segments and one J segment for just 14 possible combinations (42). Increased junctional diversity of the developing naive immunoglobulin repertoire occurs during recombination of the $\mathrm{V}(\mathrm{D}) \mathrm{J}$ segments in which exonuclease activity removes nucleotides from the segment ends and the enzyme terminal deoxynucleotidyl transferase (TdT) adds nucleotides to the segment ends (41). The substantially limited swine VDJ is overcome by exonuclease and TdT activities (42).

Antigen exposure to naive B cells leads to secretion of $\operatorname{IgM}$ antibodies with typically low average affinities $\left(\sim 10^{-7} K_{\mathrm{d}}\right)$. This low affinity is the result of the poor proximity of the amino acid residues of the antibody variable region to the residues of the antigenic epitope, thus, fewer non-covalent bonds can form at the antibody:antigen interface. However, as these B cells undergo clonal selection and expansion during an infection, somatic hypermutation (SHM) occurs in daughter cell V(D)J regions that leads to antibodies with higher average affinities by virtue of refined complimentary topology between the antibody and its epitope, and the inclusion of amino acids in the variable region that strengthen the non-covalent interactions with the epitope (43). This process, termed affinity maturation, requires $\mathrm{T}$ cell help and expression of the enzyme activation-induced cytidine deaminase (AID) in the dividing B cells. The result of this process is the generation of antibodies with affinities for antigen that are orders of magnitude greater $\left(\sim 10^{-10}\right.$ to $\sim 10^{-12}$ $K_{\mathrm{d}}$ ) than those of the original naive parental B cell clones that recognized the antigen.

Affinity maturation can take weeks, but if the host survives the infection it typically produces antibodies that can bind antigen with nearly irreversible affinities under physiological conditions. Importantly, this process leads to memory B cells that have high affinity surface immunoglobulin receptors that have already class-switched to IgG or IgA, and can rapidly divide and secrete antibodies independent of $\mathrm{T}$ cell help should the same pathogen be encountered again. Indeed, affinity maturation principally accounts for the high antibody titers detected by the various serological end-point dilution assays.

In bats, combinatorial diversity may lead to the generation of a much larger naive immunoglobulin repertoire than it does in humans because bats may possess more heavy-chain VDJ germline gene segments. The heavy-chain locus of humans has 40 functional $\mathrm{V}$ segments, $24 \mathrm{D}$ segments, and $6 \mathrm{~J}$ segments for a potential of $5,760 \mathrm{H}$ chain specificities in its naive $\mathrm{B}$ cell repertoire through combinatorial diversity (44). The little brown

TABLE 1 | Immunoglobulin gene segments of select mammalian species (42).

\begin{tabular}{|c|c|c|c|c|c|c|c|c|c|c|}
\hline Species & $\mathbf{V}_{\mathrm{H}}\left(F^{\mathrm{a}}\right)$ & $\mathbf{D}_{\mathrm{H}}$ & $\mathbf{J}_{\mathrm{H}}$ & $\mathbf{V}_{\lambda}(\boldsymbol{F})$ & $\mathbf{J}_{\lambda}$ & $\mathbf{C}_{\lambda}{ }^{\mathrm{b}}$ & $\mathbf{V}_{\mathrm{k}}(\boldsymbol{F})$ & $\mathbf{J}_{\kappa}$ & $\mathbf{C}_{\mathrm{k}}$ & $k: l^{c}$ \\
\hline Little brown bat & $>250(5)$ & $?$ & 13 & $?$ & $?$ & $?$ & $?(?)$ & $?$ & $?$ & $?: ?$ \\
\hline Human & $87(7)$ & 30 & 9 & $70(7)$ & 7 & 7 & $66(7)$ & 5 & 1 & $60: 40$ \\
\hline Mouse & $>100(14)$ & 11 & 4 & $3(3)$ & 4 & 4 & $140(4)$ & 4 & 1 & $95: 5$ \\
\hline Rabbit & $>100(1)$ & 11 & 6 & $?(?)$ & 2 & 2 & $>36(?)$ & 8 & $2^{d}$ & $95: 5$ \\
\hline Horse & $>10(2)$ & $>7$ & $>5$ & $25(3)$ & 4 & 4 & $>20(?)$ & 5 & 5 & $5: 95$ \\
\hline Cattle & $>15(2)$ & 3 & 5 & $83(8)$ & $>2$ & 4 & $?(?)$ & $?$ & 1 & 5:95 \\
\hline Swine & $>20(1)$ & $2^{e}$ & $1^{e}$ & $22(>2)$ & $>4$ & 4 & $14-60(5)$ & 5 & 1 & $50: 50$ \\
\hline
\end{tabular}

${ }^{a}$ Number of families (F) of variable region genes.

${ }^{b} J_{\lambda}-C_{\lambda}$ duplicons are the common motif in most mammals.

${ }^{c}$ Ratio of expressed light chain in adults expressed as percent.

${ }^{d}$ Rabbits have a duplicate of the entire kappa locus.

${ }^{e}$ Functional $D_{H}$ and $J_{H}$ genes.

?, number is unknown. 
bat (Myotis lucifugus) has an estimated $236 \mathrm{~V}$ segments, at least $24 \mathrm{D}$ segments, and at least $13 \mathrm{~J}$ segments, with a potential of more than 70,000 specificities in the naive B cell repertoire (9) (Figure 1). Pteropid bats also have a highly diverse genomic and expressed $V_{H}$ repertoire, and evidence for multiple expressed $\mathrm{D}_{\mathrm{H}}$ and $\mathrm{J}_{\mathrm{H}}$ segments, consistent with their ability to recognize a range of antigenic epitopes (45). Bats appear to only express $\lambda$ light chains but no research has been published about their light chain VJ segments nor their T cell receptor genes, thus it is not possible to compare them to other mammals.

In little brown bats, there appears to be less dependence on affinity maturation (9), suggesting the expanded repertoire from combinatorial diversity may have reduced, but not eliminated, the evolutionary need for SHM. Bats have and express the gene for AID (6-8), thus it is likely that some SHM occurs but AID appears to play a less prominent role in bats than it does in mice, humans, and swine. AID also facilitates class switching to other antibody classes (isotypes) in mice and humans, such as the IgG subclasses and IgA (46). If it is used less in bats, does this mean there is less class switching in bats? Or is it only the SHM function that is reduced? Do bats also generate junctional diversity through exonuclease and TdT activity? If bats do not use SHM does that lead to less robust memory B cell responses that can contribute to viral recrudescence?

Many of these questions are difficult to address because there are few immunoglobulin class-specific antibodies for bats of any species. Polyclonal rabbit antibodies to Australian black flying fox (Pteropus alecto) IgG, IgM, and IgA have been generated (47), but all others are polyclonal antibodies to whole bat IgG that likely recognize light chains as well as heavy chains. Because light chains are shared by all immunoglobulin classes, these polyclonal antibodies cannot discriminate IgD, IgM, IgG, $\operatorname{IgA}$, or IgE. The number of immunoglobulin heavy-chain genes that encode IgG subclasses vary between species, with Seba's fruit bat (Carollia perspicillata) having only one, big brown bat (Eptesicus fuscus) having two, greater short-nosed bat (Cynopterus sphinx) having three and little brown bat having five (48). One monoclonal antibody to the immunoglobulin $\lambda$ chain of the big brown bat has been generated and it has cross reactivity to little brown bat $\lambda$ chains; thus, it likely will be useful for characterizing antibodies from these bats (49).

A recent report suggested that $\operatorname{IgG}$, rather than $\operatorname{IgA}$, is more abundant in mucosal secretions of the Australian black flying fox (47). Their approach used Jacalin, peptide M, and staphylococcal superantigen-like protein 7 to purify IgA; these reagents are routinely used to purify human IgA but it is unclear if they bind bat IgA efficiently, or at all. The suggestion that IgG is the most abundant secretory immunoglobulin in bats is inconsistent with established data on secretory immunoglobulins in other mammals and should be regarded with caution. The generation of isotype-specific monoclonal antibodies to bat immunoglobulins will be required to determine which isotype is most abundant in mucosal secretions of bats.

\section{A HYPOTHESIS OF BAT IMMUNE RESPONSES TO VIRAL INFECTIONS}

We propose that innate and adaptive immune responses in bats are different than in mice and humans, and these differences may account for why the viruses they host can be significant human pathogens. First, we suggest that because of higher constitutive expression of IFN $\alpha$ and persistent ISG activity, bat cells hamper virus replication relative to what occurs in cells from humans and rodent disease models. Second, because of the apparently larger bat naive immunoglobulin repertoires (from combinatorial diversity), bats may have more immunoglobulin specificities that favor clonal selection of B cells with immunoglobulin receptors that interact with substantially higher mean affinities for antigen. Because of this, and because of the reduced viral burden due to persistent IFN activity, there has been less evolutionary pressure for SHM to control viral infections in bats-the selected B cells can undergo clonal expansion without an urgent need for affinity maturation to generate high-titered antibodies.

This combination of events may lead to several expected outcomes that can be experimentally tested. First, because of their constitutively high expression of IFN $\alpha$, less virus replication

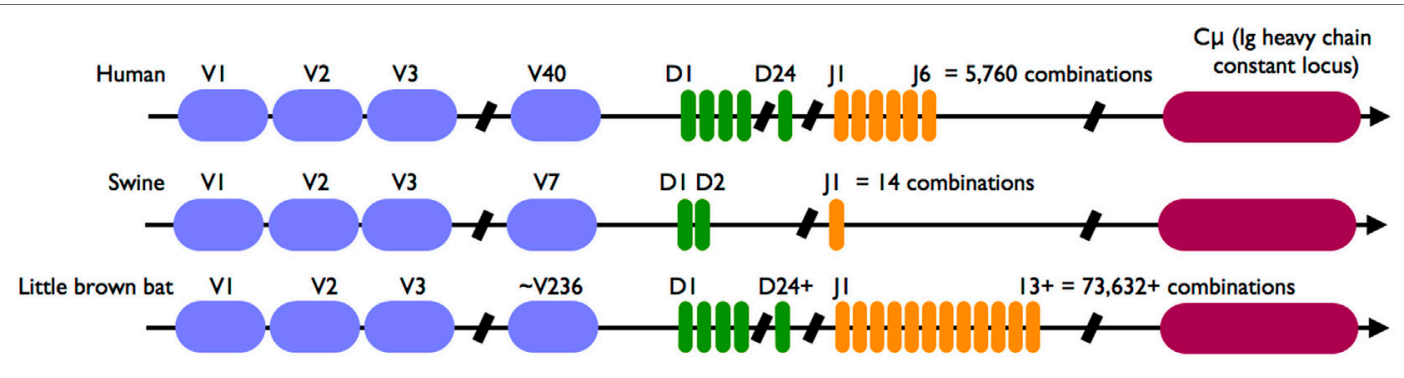

FIGURE 1 | Immunoglobulin VDJ combinatorial diversity potential of humans, swine and little brown bats. The human heavy (H) chain locus has about 40 variable (V), 24 diversity (D) and 6 joining (J) segments that are functional. Rearrangement of the locus occurs during B cell development in the bone marrow and provides the repertoire of immunoglobulin specificities that are clonotypic in naive B cells, usually with lgM constant $(\mathrm{C} \mu)$ heavy chains, which populate peripheral lymphoid tissues, such as lymph nodes and the spleen. The theoretical number of human $\mathrm{H}$ chain specificities is $40 \times 24 \times 6=5,760$. In contrast, swine have $7 \mathrm{~V}, 2 \mathrm{D}$, and 1 $\mathrm{J}$ segments that are functional, totaling 14. In the little brown bat (Myotis lucifugus), the functional $\mathrm{H}$ chain locus is estimated to have $236 \mathrm{~V}$ segments, at least $24 \mathrm{D}$ segments, and at least $13 \mathrm{~J}$ segments, for a theoretical number of at least 73,632 specificities in the naive B cell repertoire. Blue, $V$ gene segments; green, $D$ gene segments; orange, J chain segments; purple, C gene (IgM); other C genes not shown. 
should occur in infected bat cells compared to human or rodent cells used in pathology models. Second, because of the hampered viral replication, antibody responses in bats likely are slower to develop and may not be as durable as those in mice or humans because fewer viruses will be available for $\mathrm{T}$ and $\mathrm{B}$ cell stimulation. Third, antibody titers, which are a function of affinity maturation, should be lower in bats (e.g., average affinities of $10^{-9}$ to $10^{-11} K_{\mathrm{d}}$ ) than those generated in mice. A poorer antibody response (i.e., lower titer) could prevent or delay clearance of virus from the reservoir bat, contribute to persistent infection, prolong shedding, and lead to periods of recrudescence as antibody wanes.

Although there are a few bat cell lines that are susceptible to these viruses, caution must be exercised when using them because of the potential for unusual genomic events that routinely occur during immortalization, such as deletions and duplications of genes, which can complicate interpretation of data. Therefore, assessment of viral infection kinetics will require isolation of identical susceptible primary cells from reservoir bats, and humans or rodents used in pathology studies. As one example, Nipah virus infects endothelial cells (50-52) and the Syrian hamster is a pathology model for its disease $(53,54)$. Isolation of primary endothelial cells (e.g., PCAM1 ${ }^{+}$ cells) from pteropid reservoir hosts and hamsters could be used to assess virus replication kinetics. If our hypothesis is correct, then we would expect less virus replication and shedding from primary pteropid endothelial cells than from hamster endothelial cells.

Consistent with our hypothesis, bat antibody responses appear to be slower to develop and less robust during infection $(55,56)$ and immunization $(57,58)$ compared to those of mice. Immunization of Brazilian free-tailed bats (Tadarida brasiliensis) and Egyptian fruit bats (Rousettus aegyptiacus) with rabies vaccines resulted in neutralizing antibody responses that are considered protective $(59,60)$. However, the vaccines used in these studies were inactivated, thus (1) were incapable of infecting cells and influencing the IFN response with the viral accessory proteins and (2) were formulated with adjuvant that simulates inflammation that contributes to more robust antibody responses. Experimental Marburg virus infection of Egyptian fruit bats, a natural reservoir host, leads to brief viremia, wide tissue distribution and low to modest viral loads and seroconversion (61-63) and transmission (64). Similarly, poor neutralizing antibody responses occur after experimental infection of artibeus bats with Tacaribe virus, even in surviving bats (65). To date, no direct comparisons of infections with bat-borne viruses in reservoir host bats and pathology models have been performed; thus, there are no direct comparisons of the antibody responses to determine differences or similarities between bats and other mammals. In addition to immune response studies of apathogenic infection of bat reservoir hosts and their viruses, it will be necessary to examine the immune response in pathogenic infections of bats for essential comparison, such as the aforementioned Tacaribe virus infection of artibeus bats (65) or rabies virus infection of bats of many species $(60,66)$. After all, if bat IFN responses are "always on," why does Tacaribe virus kill bats?

\section{HAS PERSISTENT IFN ACTIVITY IN BATS DRIVEN THE EVOLUTION OF VIRUSES PATHOGENIC TO HUMANS?}

With persistent activation of the IFN response in bat cells, it is reasonable to assume that viruses hosted by bats have evolved finely tuned countermeasures to dampen the response in the reservoir bat species. For example, STAT1, an essential component of the type I, II, and III IFN receptor signaling pathways, is a target of ebolavirus VP24, Marburg virus VP40, Nipah virus V and W, and SARS-CoV ORF6 (67-71). Because the viruses have evolved in bats, these proteins are likely optimized to disrupt STAT1 activity in the reservoir host bats in a qualitative and/or quantitative manner that permits virus replication and shedding without compromising the health of the host. Hendra virus antagonizes IFN production and signaling in an immortalized cell line from the Australian black flying fox, but only disrupts IFN production in an immortalized human cell line $(72,73)$. The impact of these proteins on STAT1 in the reservoir bats must be enough to allow some, perhaps periodic, viral replication to sustain the virus in bat populations, but not so much that it leads to high levels of viral replication and shedding from infected cells; otherwise, pathology and/or a robust adaptive immune response would ensue. But because the IFN receptor pathway is persistently activated in bat cells, it is likely that expression of these viral proteins occurs to counteract STAT1's cascading activation of the ISG pathways. Another important caveat of the experimental systems used to examine the effects of these viral proteins is that their genes are often cloned into high-expression plasmids or into other viruses that do not naturally infect bats. It is probable that expression levels of these genes by their viruses have been evolutionarily optimized for the reservoir bat species. But this presents logistical difficulties because most of these viruses require BSL-3 or BSL-4 containment, a significant hurdle for many investigators.

STAT1 is a highly conserved protein and the viral accessory proteins that target it have been shown to often interfere with human STAT1 activity (67-71). We hypothesize that because of persistent IFN activity in bat cells, these viruses may express these accessory proteins at substantially higher levels to counter the bat cell's elevated basal levels of the IFN response genes (Figure 2). STAT1 of the Australian black flying fox (Hendra virus reservoir) and the Egyptian fruit bat (R. aegyptiacus, Marburg virus reservoir) are $96 \%$ and $97 \%$ identical, respectively, to human STAT1. Because the human IFN system is "off" (i.e., low basal levels) until an infection, it may be that these viral proteins are expressed in such high abundance immediately upon infection of a human cell (because they have been evolutionarily programmed in bat cells) that they abrogate the cell's ability to mount an effective IFN response. This could lead to abundant viral replication and shedding from human cells, which would then disseminate and infect other cells, leading to direct viral pathology or immunopathology from the subsequent activation of immune cells that respond to viral infection, including macrophages, neutrophils, NK cells and cytotoxic T cells. Alternatively, or in conjunction with, the viral proteins may bind to STAT1 of humans and bats with different affinities that could contribute to the dichotomous outcomes (72). 

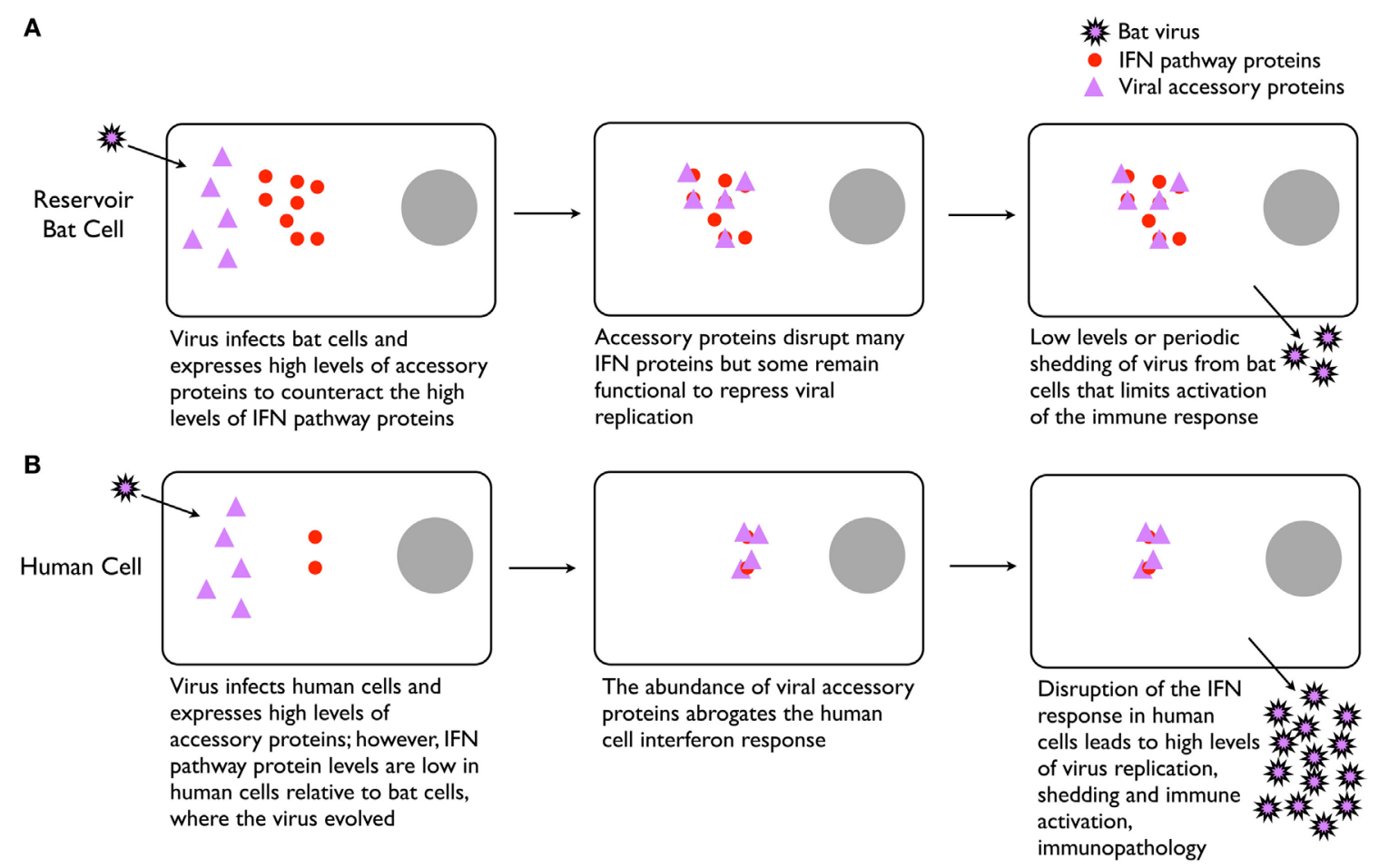

FIGURE 2 | Potential explanation for high virulence of certain bat-borne viruses in humans. (A) Infection of bat cells leads to high expression of viral accessory proteins that repress the constitutively active type I interferon (IFN) system, leading to low levels of virus replication and shedding. Low level or intermittent replication of virus delays and reduces stimulation of the immune system, thus resulting in weak adaptive immunity and poor antibody responses. (B) In human cells, the high expression of viral accessory proteins significantly disrupts the cell's ability to control the infection, leading to high levels of virus replication and immune stimulation that contributes to pathogenesis.

\section{CAVEATS AND CHALLENGES OF THE HYPOTHESIS}

We recognize that this hypothesis on its own may be insufficient to explain the biological relationships and interactions of hundreds of viruses, and probably many more (74), and bats of the $\sim 1,200$ different species. Is the IFN system "always on" for all 1,200 species of bats? Do they all have more V(D)J germline gene segments? Do they all rely more on combinatorial diversity and less on SHM for the generation of their immunoglobulin repertoires? Just as there are significant differences between bats and other mammals, there are likely significant differences between bat species. However, considering the current evidence, we believe that several aspects of these hypotheses can be experimentally addressed with appropriate animal studies. We also have not considered other aspects of immune systems that may be important in chiropteran immunology, including activities of cellular immunity, the roles of complement and antibody-dependent cell cytotoxicity, immune effector molecules such as cytokines, antigen processing and presentation, immunological memory, and the myriad other immunological factors. Virtually nothing is known about these aspects of bat immunology, thus it is difficult to imagine how they might be different or contribute to bats of a particular species being suitable reservoir hosts for viruses of a particular species. It also is likely that many other differences between bats and other mammals exist that are not directly related to the immune response (e.g., metabolism, physiology, hormonal changes, behavior, "flight as fever") that are contributory factors to reservoir host status of bats.

Of what is known, experimental approaches that examine the responses of infected bat cells (e.g., IFN response) and antibody responses seem to be the most tractable. A significant hurdle to accomplish these experiments is the lack of well-defined bat models for infectious disease research. Few closed colonies of bats are available for such purposes and of those, few reagents and methodologies have been developed to exploit them. These deficiencies can be rapidly overcome using the technological tools available today. For example, collection of low abundance antibodies (i.e., IgM, IgA) or immune cells from bats is challenging; most microbats are so small that collection of a few hundred microliters of blood can be lethal. But with deep sequencing, full genomes and transcriptomes can be rapidly generated and exploited to produce nearly any recombinant bat protein for use in experimental work. This approach could be deployed to generate monoclonal antibodies specific to not only $\operatorname{IgM}$ and IgA, but IgG subclasses, to help understand immune responses in bats. Moreover, with long-read RNA-Seq and bioinformatics, characterization of immunoglobulin and $\mathrm{T}$ cell receptor repertoires can identify 
increased frequencies of $\mathrm{V}(\mathrm{D}) \mathrm{J}$ usage during $\mathrm{B}$ and $\mathrm{T}$ cell clonal expansion and SHM during infection $(75,76)$. This should clarify to what degree SHM is used by bats during immune responses, which has only been examined in naive little brown bats (9).

Regardless of the virus, it is essential that experimental infection studies of bat viruses should be done in bats. The use of other species, such as rodents and non-human primates, may provide information about pathogenesis, but they cannot address the biology, evolution and ecology of bat-borne viruses, and how they may emerge as human pathogens.

\section{REFERENCES}

1. Calisher CH, Childs JE, Field HE, Holmes KV, Schountz T. Bats: important reservoir hosts of emerging viruses. Clin Microbiol Rev (2006) 19(3):531-45. doi:10.1128/CMR.00017-06

2. Lau SK, Li KS, Tsang AK, Lam CS, Ahmed S, Chen H, et al. Genetic characterization of Betacoronavirus lineage $\mathrm{C}$ viruses in bats reveals marked sequence divergence in the spike protein of pipistrellus bat coronavirus HKU5 in Japanese pipistrelle: implications for the origin of the novel Middle East respiratory syndrome coronavirus. J Virol (2013) 87(15):8638-50. doi:10.1128/ JVI.01055-13

3. Luis AD, Hayman DT, O'Shea TJ, Cryan PM, Gilbert AT, Pulliam JR, et al. A comparison of bats and rodents as reservoirs of zoonotic viruses: are bats special? Proc Biol Sci (2013) 280(1756):20122753. doi:10.1098/rspb. 2012.2753

4. Olival KJ, Hosseini PR, Zambrana-Torrelio C, Ross N, Bogich TL, Daszak P. Host and viral traits predict zoonotic spillover from mammals. Nature (2017) 546(7660):646-50. doi:10.1038/nature22975

5. Benton MJ, Ayala FJ. Dating the tree oflife. Science (2003) 300(5626):1698-700. doi:10.1126/science.1077795

6. Papenfuss AT, Baker ML, Feng ZP, Tachedjian M, Crameri G, Cowled C, et al. The immune gene repertoire of an important viral reservoir, the Australian black flying fox. BMC Genomics (2012) 13(1):261. doi:10.1186/14712164-13-261

7. Shaw TI, Srivastava A, Chou WC, Liu L, Hawkinson A, Glenn TC, et al. Transcriptome sequencing and annotation for the Jamaican fruit bat (Artibeus jamaicensis). PLoS One (2012) 7(11):e48472. doi:10.1371/journal. pone. 0048472

8. Zhang G, Cowled C, Shi Z, Huang Z, Bishop-Lilly KA, Fang X, et al. Comparative analysis of bat genomes provides insight into the evolution of flight and immunity. Science (2013) 339(6118):456-60. doi:10.1126/ science. 1230835

9. Bratsch S, Wertz N, Chaloner K, Kunz TH, Butler JE. The little brown bat, M. lucifugus, displays a highly diverse $\mathrm{V} \mathrm{H}, \mathrm{D} \mathrm{H}$ and $\mathrm{J} \mathrm{H}$ repertoire but little evidence of somatic hypermutation. Dev Comp Immunol (2011) 35(4):421-30. doi:10.1016/j.dci.2010.06.004

10. Zhou P, Tachedjian M, Wynne JW, Boyd V, Cui J, Smith I, et al. Contraction of the type I IFN locus and unusual constitutive expression of IFN-alpha in bats. Proc Natl Acad Sci U S A (2016) 113(10):2696-701. doi:10.1073/ pnas. 1518240113

11. Ahn M, Cui J, Irving AT, Wang LF. Unique loss of the PYHIN gene family in bats amongst mammals: implications for inflammasome sensing. Sci Rep (2016) 6:21722. doi:10.1038/srep21722

12. Baker ML, Schountz T, Wang LF. Antiviral immune responses of bats: a review. Zoonoses Public Health (2013) 60(1):104-16. doi:10.1111/j.1863-2378.2012.01528.x

13. Schountz T. Immunology of bats and their viruses: challenges and opportunities. Viruses (2014) 6(12):4880-901. doi:10.3390/v6124880

14. Bean AG, Baker ML, Stewart CR, Cowled C, Deffrasnes C, Wang LF, et al. Studying immunity to zoonotic diseases in the natural host-keeping it real. Nat Rev Immunol (2013) 13(12):851-61. doi:10.1038/ nri3551

\section{AUTHOR CONTRIBUTIONS}

All authors listed have made substantial, direct, and intellectual contribution to the work and approved it for publication.

\section{ACKNOWLEDGMENTS}

The authors thank Charles $\mathrm{H}$. Calisher for review of the manuscript and Jacalyn S. Strong for support. VM is supported by the Intramural Research Program of the National Institute of Allergy and Infectious Diseases, National Institutes of Health.

15. Schountz T, Prescott J. Hantavirus immunology of rodent reservoirs: current status and future directions. Viruses (2014) 6(3):1317-35. doi:10.3390/ v6031317

16. Mandl JN, Ahmed R, Barreiro LB, Daszak P, Epstein JH, Virgin HW, et al. Reservoir host immune responses to emerging zoonotic viruses. Cell (2015) 160(1-2):20-35. doi:10.1016/j.cell.2014.12.003

17. Drexler JF, Corman VM, Wegner T, Tateno AF, Zerbinati RM, Gloza-Rausch F, et al. Amplification of emerging viruses in a bat colony. Emerg Infect Dis (2011) 17(3):449-56. doi:10.3201/eid1703.100526

18. Yanagihara R, Amyx HL, Gajdusek DC. Experimental infection with Puumala virus, the etiologic agent of nephropathia epidemica, in bank voles (Clethrionomys glareolus). J Virol (1985) 55(1):34-8.

19. Botten J, Mirowsky K, Kusewitt D, Bharadwaj M, Yee J, Ricci R, et al. Experimental infection model for Sin Nombre hantavirus in the deer mouse (Peromyscus maniculatus). Proc Natl Acad Sci U S A (2000) 97(19):10578-83. doi:10.1073/pnas.180197197

20. Botten J, Mirowsky K, Kusewitt D, Ye C, Gottlieb K, Prescott J, et al. Persistent Sin Nombre virus infection in the deer mouse (Peromyscus maniculatus) model: sites of replication and strand-specific expression. J Virol (2003) 77(2):1540-50. doi:10.1128/JVI.77.2.1540-1550.2002

21. Schountz T, Acuna-Retamar M, Feinstein S, Prescott J, Torres-Perez F, PodellB, etal.Kineticsofimmuneresponsesindeermiceexperimentallyinfected with Sin Nombre virus. J Virol (2012) 86(18):10015-27. doi:10.1128/JVI. 06875-11

22. McGuire A, Miedema K, Fauver JR, Rico A, Aboellail T, Quackenbush SL, et al. Maporal hantavirus causes mild pathology in deer mice (Peromyscus maniculatus). Viruses (2016) 8(10):E286. doi:10.3390/v8100286

23. Easterbrook JD, Zink MC, Klein SL. Regulatory T cells enhance persistence of the zoonotic pathogen Seoul virus in its reservoir host. Proc Natl Acad Sci U S A (2007) 104(39):15502-7. doi:10.1073/pnas.0707453104

24. Schountz T, Prescott J, Cogswell AC, Oko L, Mirowsky-Garcia K, Galvez AP, et al. Regulatory $\mathrm{T}$ cell-like responses in deer mice persistently infected with Sin Nombre virus. Proc Natl Acad Sci U S A (2007) 104(39):15496-501. doi:10.1073/pnas.0707454104

25. Basler CF. Nipah and hendra virus interactions with the innate immune system. Curr Top Microbiol Immunol (2012) 359:123-52. doi:10.1007/82 2012_209

26. Mathieu C, Guillaume V, Volchkova VA, Pohl C, Jacquot F, Looi RY, et al. Nonstructural Nipah virus $C$ protein regulates both the early host proinflammatory response and viral virulence. J Virol (2012) 86(19):10766-75. doi:10.1128/JVI.01203-12

27. Ramanan P, Edwards MR, Shabman RS, Leung DW, Endlich-Frazier AC, Borek DM, et al. Structural basis for Marburg virus VP35-mediated immune evasion mechanisms. Proc Natl Acad Sci U S A (2012) 109(50):20661-6. doi:10.1073/ pnas. 1213559109

28. Gralinski LE, Baric RS. Molecular pathology of emerging coronavirus infections. J Pathol (2015) 235(2):185-95. doi:10.1002/path.4454

29. Volchkova VA, Dolnik O, Martinez MJ, Reynard O, Volchkov VE. RNA editing of the GP gene of Ebola virus is an important pathogenicity factor. I Infect Dis (2015) 212(Suppl 2):S226-33. doi:10.1093/infdis/jiv309

30. Warren TK, Whitehouse CA, Wells J, Welch L, Heald AE, Charleston JS, et al. A single phosphorodiamidate morpholino oligomer targeting VP24 
protects rhesus monkeys against lethal Ebola virus infection. MBio (2015) 6(1):e2344-2314. doi:10.1128/mBio.02344-14

31. Banadyga L, Dolan MA, Ebihara H. Rodent-adapted filoviruses and the molecular basis of pathogenesis. J Mol Biol (2016) 428(17):3449-66. doi:10.1016/j. jmb.2016.05.008

32. Thornbrough JM, Jha BK, Yount B, Goldstein SA, Li Y, Elliott R, et al. Middle east respiratory syndrome coronavirus NS4b protein inhibits host RNase L activation. MBio (2016) 7(2):e00258. doi:10.1128/mBio.00258-16

33. O'Shea TJ, Cryan PM, Cunningham AA, Fooks AR, Hayman DT, Luis AD, et al. Bat flight and zoonotic viruses. Emerg Infect Dis (2014) 20(5):741-5. doi:10.3201/eid2005.130539

34. Ching S, Zhang H, Belevych N, He L, Lai W, Pu XA, et al. Endothelial-specific knockdown of interleukin-1 (IL-1) type 1 receptor differentially alters CNS responses to IL-1 depending on its route of administration. J Neurosci (2007) 27(39):10476-86. doi:10.1523/JNEUROSCI.3357-07.2007

35. Wilhelms DB, Kirilov M, Mirrasekhian E, Eskilsson A, Kugelberg UO, Klar C, et al. Deletion of prostaglandin E2 synthesizing enzymes in brain endothelial cells attenuates inflammatory fever. J Neurosci (2014) 34(35):11684-90. doi:10.1523/JNEUROSCI.1838-14.2014

36. Miller MR, McMinn RJ, Misra V, Schountz T, Muller MA, Kurth A, et al. Broad and temperature independent replication potential of filoviruses on cells derived from old and new world bat species. J Infect Dis (2016) 214 (Suppl 3):S297-302. doi:10.1093/infdis/jiw199

37. Brook CE, Dobson AP. Bats as 'special' reservoirs for emerging zoonotic pathogens. Trends Microbiol (2015) 23(3):172-80. doi:10.1016/j.tim.2014. 12.004

38. Zhou P, Cowled C, Marsh GA, Shi Z, Wang LF, Baker ML. Type III IFN receptor expression and functional characterisation in the pteropid bat, Pteropus alecto. PLoS One (2011) 6(9):e25385. doi:10.1371/journal.pone. 0025385

39. Zhou P, Cowled C, Todd S, Crameri G, Virtue ER, Marsh GA, et al. Type III IFNs in pteropid bats: differential expression patterns provide evidence for distinct roles in antiviral immunity. J Immunol (2011) 186(5):3138-47. doi:10.4049/jimmunol.1003115

40. Jung D, Giallourakis C, Mostoslavsky R, Alt FW. Mechanism and control of V(D)J recombination at the immunoglobulin heavy chain locus. Annu Rev Immunol (2006) 24:541-70. doi:10.1146/annurev.immunol.23.021704. 115830

41. Jackson KJ, Kidd MJ, Wang Y, Collins AM. The shape of the lymphocyte receptor repertoire: lessons from the B cell receptor. Front Immunol (2013) 4: 263. doi: $10.3389 /$ fimmu. 2013.00263

42. Butler JE, Wertz N. The porcine antibody repertoire: variations on the textbook theme. Front Immunol (2012) 3:153. doi:10.3389/fimmu.2012. 00153

43. Peled JU, Kuang FL, Iglesias-Ussel MD, Roa S, Kalis SL, Goodman MF, et al. The biochemistry of somatic hypermutation. Annu Rev Immunol (2008) 26:481-511. doi:10.1146/annurev.immunol.26.021607.090236

44. Max EE, Fugmann S. Fundamental Immunology. Philadelphia: Lippincott (2013).

45. Baker ML, Tachedjian M, Wang LF. Immunoglobulin heavy chain diversity in Pteropid bats: evidence for a diverse and highly specific antigen binding repertoire. Immunogenetics (2010) 62(3):173-84. doi:10.1007/s00251010-0425-4

46. Stavnezer J, Guikema JE, Schrader CE. Mechanism and regulation of class switch recombination. Annu Rev Immunol (2008) 26:261-92. doi:10.1146/ annurev.immunol.26.021607.090248

47. Wynne JW, Di Rubbo A, Shiell BJ, Beddome G, Cowled C, Peck GR, et al. Purification and characterisation of immunoglobulins from the Australian black flying fox (Pteropus alecto) using anti-fab affinity chromatography reveals the low abundance of IgA. PLoS One (2013) 8(1):e52930. doi:10.1371/ journal.pone. 0052930

48. Butler JE, Wertz N, Zhao Y, Zhang S, Bao Y, Bratsch S, et al. The two suborders of chiropterans have the canonical heavy-chain immunoglobulin (Ig) gene repertoire of eutherian mammals. Dev Comp Immunol (2011) 35(3):273-84. doi:10.1016/j.dci.2010.08.011

49. Lee WT, Jones DD, Yates JL, Winslow GM, Davis AD, Rudd RJ, et al. Identification of secreted and membrane-bound bat immunoglobulin using a Microchiropteran-specific mouse monoclonal antibody. Dev Comp Immunol (2016) 65:114-23. doi:10.1016/j.dci.2016.06.024
50. Chua KB, Bellini WJ, Rota PA, Harcourt BH, Tamin A, Lam SK, et al. Nipah virus: a recently emergent deadly paramyxovirus. Science (2000) 288(5470):1432-5. doi:10.1126/science.288.5470.1432

51. Negrete OA, Levroney EL, Aguilar HC, Bertolotti-Ciarlet A, Nazarian R, Tajyar S, et al. EphrinB2 is the entry receptor for Nipah virus, an emergent deadly paramyxovirus. Nature (2005) 436(7049):401-5. doi:10.1038/ nature 03838

52. Lo MK, Miller D, Aljofan M, Mungall BA, Rollin PE, Bellini WJ, et al. Characterization of the antiviral and inflammatory responses against Nipah virus in endothelial cells and neurons. Virology (2010) 404(1):78-88. doi:10.1016/j.virol.2010.05.005

53. Wong KT, Grosjean I, Brisson C, Blanquier B, Fevre-Montange M, Bernard A, et al. A golden hamster model for human acute Nipah virus infection. Am J Pathol (2003) 163(5):2127-37. doi:10.1016/ S0002-9440(10)63569-9

54. de Wit E, Bushmaker T, Scott D, Feldmann H, Munster VJ. Nipah virus transmission in a hamster model. PLoS Negl Trop Dis (2011) 5(12):e1432. doi:10.1371/journal.pntd.0001432

55. Williamson MM, Hooper PT, Selleck PW, Gleeson LJ, Daniels PW, Westbury HA, et al. Transmission studies of Hendra virus (equine morbillivirus) in fruit bats, horses and cats. Aust Vet J (1998) 76(12):813-8. doi:10.1111/j. 1751-0813.1998.tb12335.x

56. Halpin K, Hyatt AD, Fogarty R, Middleton D, Bingham J, Epstein JH, et al. Pteropid bats are confirmed as the reservoir hosts of henipaviruses: a comprehensive experimental study of virus transmission. Am J Trop Med Hyg (2011) 85(5):946-51. doi:10.4269/ajtmh.2011.10-0567

57. Chakraborty AK, Chakravarty AK. Antibody-mediated immune response in the bat, Pteropus giganteus. Dev Comp Immunol (1984) 8(2):415-23. doi:10.1016/0145-305X(84)90048-X

58. Wellehan JF Jr, Green LG, Duke DG, Bootorabi S, Heard DJ, Klein PA, et al. Detection of specific antibody responses to vaccination in variable flying foxes (Pteropus hypomelanus). Comp Immunol Microbiol Infect Dis (2009) 32(5):379-94. doi:10.1016/j.cimid.2007.11.002

59. Peters C, Isaza R, Heard DJ, Davis RD, Moore SM, Briggs DJ. Vaccination of Egyptian fruit bats (Rousettus aegyptiacus) with monovalent inactivated rabies vaccine. J Zoo Wildl Med (2004) 35(1):55-9. doi:10.1638/03-027

60. Turmelle AS, Allen LC, Schmidt-French BA, Jackson FR, Kunz TH, $\mathrm{McCracken} \mathrm{GF,} \mathrm{et} \mathrm{al.} \mathrm{Response} \mathrm{to} \mathrm{vaccination} \mathrm{with} \mathrm{a} \mathrm{commercial} \mathrm{inactivated}$ rabies vaccine in a captive colony of Brazilian free-tailed bats (Tadarida brasiliensis). JZoo Wildl Med (2010) 41(1):140-3. doi:10.1638/20080161.1

61. Paweska JT, Jansen van Vuren P, Masumu J, Leman PA, Grobbelaar AA, Birkhead M, et al. Virological and serological findings in Rousettus aegyptiacus experimentally inoculated with vero cells-adapted Hogan strain of Marburg virus. PLoS One (2012) 7(9):e45479. doi:10.1371/journal.pone. 0045479

62. Amman BR, Jones ME, Sealy TK, Uebelhoer LS, Schuh AJ, Bird BH, et al Oral shedding of Marburg virus in experimentally infected Egyptian fruit bats (Rousettus aegyptiacus). JWildl Dis (2015) 51(1):113-24. doi:10.7589/2014-08-198

63. Paweska JT, Jansen van Vuren P, Fenton KA, Graves K, Grobbelaar AA, Moolla N, et al. Lack of Marburg virus transmission from experimentally infected to susceptible in-contact Egyptian fruit bats. J Infect Dis (2015) 212(Suppl 2):S109-18. doi:10.1093/infdis/jiv132

64. Schuh AJ, Amman BR, Jones ME, Sealy TK, Uebelhoer LS, Spengler JR, et al. Modelling filovirus maintenance in nature by experimental transmission of Marburg virus between Egyptian rousette bats. Nat Commun (2017) 8:14446. doi:10.1038/ncomms14446

65. Cogswell-Hawkinson A, Bowen R, James S, Gardiner D, Calisher CH, Adams R, et al. Tacaribe virus causes fatal infection of an ostensible reservoir host, the Jamaican fruit bat. J Virol (2012) 86(10):5791-9. doi:10.1128/ JVI.00201-12

66. Turmelle AS, Jackson FR, Green D, McCracken GF, Rupprecht CE. Host immunity to repeated rabies virus infection in big brown bats. J Gen Virol (2010) 91(Pt 9):2360-6. doi:10.1099/vir.0.020073-0

67. Shaw ML, Garcia-Sastre A, Palese P, Basler CF. Nipah virus V and W proteins have a common STAT1-binding domain yet inhibit STAT1 activation from the cytoplasmic and nuclear compartments, respectively. J Virol (2004) 78(11):5633-41. doi:10.1128/JVI.78.11.5633-5641.2004 
68. Frieman M, Yount B, Heise M, Kopecky-Bromberg SA, Palese P, Baric RS. Severe acute respiratory syndrome coronavirus ORF6 antagonizes STAT1 function by sequestering nuclear import factors on the rough endoplasmic reticulum/Golgi membrane. J Virol (2007) 81(18):9812-24. doi:10.1128/ JVI.01012-07

69. Kopecky-Bromberg SA, Martinez-Sobrido L, Frieman M, Baric RA, Palese P. Severe acute respiratory syndrome coronavirus open reading frame (ORF) $3 b$, ORF 6, and nucleocapsid proteins function as interferon antagonists. J Virol (2007) 81(2):548-57. doi:10.1128/JVI.01782-06

70. Valmas C, Grosch MN, Schumann M, Olejnik J, Martinez O, Best SM, et al. Marburg virus evades interferon responses by a mechanism distinct from Ebola virus. PLoS Pathog (2010) 6(1):e1000721. doi:10.1371/journalppat. 1000721

71. Zhang AP, Bornholdt ZA, Liu T, Abelson DM, Lee DE, Li S, et al. The ebola virus interferon antagonist VP24 directly binds STAT1 and has a novel, pyramidal fold. PLoS Pathog (2012) 8(2):e1002550. doi:10.1371/journal. ppat. 1002550

72. Virtue ER, Marsh GA, Baker ML, Wang LF. Interferon production and signaling pathways are antagonized during henipavirus infection of fruit bat cell lines. PLoS One (2011) 6(7):e22488. doi:10.1371/journal.pone.0022488

73. Virtue ER, Marsh GA, Wang LF. Interferon signaling remains functional during henipavirus infection of human cell lines. J Virol (2011) 85(8):4031-4. doi:10.1128/JVI.02412-10
74. Anthony SJ, Epstein JH, Murray KA, Navarrete-Macias I, ZambranaTorrelio CM, Solovyov A, et al. A strategy to estimate unknown viral diversity in mammals. MBio (2013) 4(5):e598-513. doi:10.1128/mBio.00598-13

75. Blachly JS, Ruppert AS, Zhao W, Long S, Flynn J, Flinn I, et al. Immunoglobulin transcript sequence and somatic hypermutation computation from unselected RNA-seq reads in chronic lymphocytic leukemia. Proc Natl Acad Sci U S A (2015) 112(14):4322-7. doi:10.1073/pnas. 1503587112

76. Neave MJ, Sunarto A, McColl KA. Transcriptomic analysis of common carp anterior kidney during Cyprinid herpesvirus 3 infection: immunoglobulin repertoire and homologue functional divergence. Sci Rep (2017) 7:41531. doi:10.1038/srep41531

Conflict of Interest Statement: The authors declare that the research was conducted in the absence of any commercial or financial relationships that could be construed as a potential conflict of interest.

Copyright (C) 2017 Schountz, Baker, Butler and Munster. This is an open-access article distributed under the terms of the Creative Commons Attribution License (CC BY). The use, distribution or reproduction in other forums is permitted, provided the original author(s) or licensor are credited and that the original publication in this journal is cited, in accordance with accepted academic practice. No use, distribution or reproduction is permitted which does not comply with these terms. 